\title{
Abordagem diagnóstica de crianças com atraso do desenvolvimento e deficiência intelectual
}

\author{
Raquel Boy ${ }^{1, *}$
}

\begin{abstract}
Resumo
Atraso no desenvolvimento ou deficiência intelectual são motivos comuns de avaliação diagnóstica pelo pediatra. Existe uma multiplicidade de causas, muitas de origem genética, com comorbidades e implicações de manejo da criança e da família. O objetivo desta revisão narrativa é descrever uma abordagem diagnóstica sob a ótica da genética médica para a criança com atraso global no desenvolvimento ou deficiência intelectual, provendo um guia atualizado para auxiliar o pediatra. Aspectos conceituais e benefícios do diagnóstico precoce, também são abordados. Métodos complementares diversos e modernos têm contribuído para o aumento dos índices de diagnósticos causais e serão expostos sucintamente.
\end{abstract}

Descritores: Atraso no desenvolvimento; Deficiência intelectual; Genética; Diagnóstico.

\begin{abstract}
Diagnostic assessment of children with global developmental delay and intellectual disabilities

Global developmental delay and intellectual disabilities are common reasons for diagnostic assessment by paediatricians. There are a multiplicity of possible causes many of which have genetic, management and treatment implications for the child and family. The purpose of this narrative revision is to describe an optimal medical genetics evaluation of the child with intellectual disability (ID) or global developmental delays to assist the practitioner. Conceptual aspects and benefits of early diagnosis of these disorders, are also covered. Several modern and complementary methods have contributed to the increased rates of causal diagnosis and will be displayed briefly.
\end{abstract}

Keywords: Developmental delay; Intellectual disability; Genetics; Diagnosis.

\section{Resumen}

Evaluación del diagnóstico de niños con retraso global del desarrollo y discapacidad intelectual

El retraso global del desarrollo y la discapacidad intelectual son las razones más comunes para que un pediatra efectúe evaluación de diagnóstico. Hay una multiplicidad de causas, muchas de origen genético, con comorbilidad e implicaciones en el control de los niños y la familia. El propósito de esta revisión narrativa es describir un enfoque de diagnóstico desde el punto de vista de la genética médica para el niño con retraso global del desarrollo o discapacidad intelectual, proporcio-
1. Departamento de Pediatria. Hospital Universitário Pedro Ernesto. Universidade do Estado do Rio de Janeiro. Rio de Janeiro, RJ.

\section{*Endereço para correspondência:}

Praia de Botafogo, 528, bloco B, apto 1202

Rio de Janeiro, RJ, Brasil.CEP: 22250-040.

E-mail: raquelboy1@gmail.com

Revista HUPE, Rio de Janeiro, 2016;15(2):177-186

doi: 10.12957/rhupe.2016.28244

Recebido em 27/06/2016. Aprovado em 16/09/2016.

nando una guía actualizada para ayudar al pediatra. Aspectos conceptuales y ventajas del diagnóstico precoz, también son abordados. Varios métodos modernos y complementarios han contribuido al aumento de las tasas de diagnóstico causal y se mostrarán brevemente.

Palabras clave: Retraso en el desarrollo; Discapacidad intelectual; Genética; Diagnóstico.

\section{Introdução}

A emergência de doenças crônico-degenerativas e suas complicações e comorbidades têm feito parte da mudança no panorama brasileiro das doenças da infância. ${ }^{1}$ Neste cenário, a ocorrência de atraso global no desenvolvimento (AGD) e a deficiência intelectual (DI) despontam como condições pediátricas relativamente comuns, atingindo até cerca de 3\% da população com uma multiplicidade de causas, muitas das quais genéticas em sua origem e com implicações no manejo e tratamento da criança e de sua família. ${ }^{2}$ Vale destacar que o termo deficiência intelectual suplantou o termo retardo mental, que deve ser evitado por ser considerado pejorativo. Em geral, em tais situações, o pediatra é o primeiro profissional a lidar diretamente com estes pacientes e seus familiares.

A importância do diagnóstico etiológico do AGD/ DI, embora difícil, é justificada pelos benefícios associados, que ultrapassam a eventualidade da cura, em especial quando realizados precocemente. Esses benefícios são citados de forma sucinta, a partir da adaptação do exposto na tabela $1 .^{3-4}$

A partir deste esclarecimento etiológico, na existência de causas genéticas, a oferta do aconselhamento 


\section{Artigo de revisão}

genético (AG) pode ser provida pelo médico geneticista clínico. É importante sinalizar que o AG é um procedimento informativo que lida não apenas com a transmissão do diagnóstico, prognóstico, discussão de mecanismos genéticos e riscos de ocorrência e dos riscos de recorrência, mas também com orientações não diretivas quanto ao planejamento familiar e utilização de medidas diagnósticas pré-concepcionais e pré-natais. Dessa forma, faz-se necessária a adequada abordagem diagnóstica, e esta demandará trabalho multidisciplinar.

Em seguida, serão apresentados alguns conceitos importantes para a compreensão do AGD e da DI e as linhas gerais da abordagem da criança com DI, voltados principalmente para o diagnóstico etiológico, por meio de investigação apropriada, de forma racionalizada, à luz das recentes tecnologias disponíveis.

\section{Atraso global do desenvolvimento e deficiência intelectual}

O AGD é definido como um atraso significativo em dois ou mais domínios do desenvolvimento, incluindo coordenação motora, linguagem, cognição social/pessoal e atividades da vida diária; sua presença pode ser preditiva de um futuro diagnóstico de DI. ${ }^{5}$

A DI compreende um grupo bastante heterogêneo, com terminologias, definições e classificações variadas. A Associação Americana em Deficiência Intelectual e do

Tabela 1. Benefícios do diagnóstico precoce da criança com AGD e DI.

1. Diminuição do sofrimento familiar

2. Provisão do prognóstico ou do curso clinico esperado

3. Discussão dos mecanismos genéticos e riscos de recorrência

4. Diminuição de exames desnecessários

5. Promoção do tratamento específico (quando houver)

6. Estabelecimento de planos de supervisão de saúde específicos

7. Acesso a protocolos de pesquisa em tratamentos

8. Promoção de suporte familiar grupo-específico

9. Possibilidade de discussão de estratégias de planejamento familiar e aplicação de testes diagnósticos pré-natais

10. Promoção da inserção precoce em programas de estimulação e educação especializadas desenvolvimento define DI como "um funcionamento intelectual significativamente abaixo da média, manifestado antes dos 18 anos de idade, coexistente com uma limitação em duas ou mais das seguintes áreas adaptativas: comunicação, cuidados pessoais, atividades cotidianas, atividades sociais, vida comunitária, autocontrole, saúde e segurança, atividades acadêmicas, de lazer e de trabalho". ${ }^{6}$

A ocorrência da DI pode se tornar evidente durante os primeiros anos de idade, manifestando-se como um atraso global do desenvolvimento. No entanto, a recíproca nem sempre é verdadeira. O termo atraso global do desenvolvimento é restrito para as crianças abaixo dos cinco anos de idade. O diagnóstico da DI reserva-se para crianças acima de 5 anos de idade, ${ }^{3}$ em função da melhor aplicabilidade dos testes de QI, da avaliação da função adaptativa e do fato de que a criança com atraso global do desenvolvimento não apresentará, necessariamente, $\mathrm{DI}^{6}$

Diversas condições como paralisia cerebral, algumas doenças neuromusculares e privação ambiental precoce podem levar ao atraso no desenvolvimento e serão evidenciadas, em idade adequada, em testes cognitivos.

\section{Classificação}

Indivíduos com DI constituem grupo muito diverso, tanto em suas manifestações clínicas quanto nas causas de suas deficiências. Diversos sistemas de classificação foram propostos, ${ }^{6,7}$ a maioria dos quais aborda um dos seguintes aspectos:

1) Quanto à gravidade das manifestações clínicas, determina-se o grau da deficiência mental: DI severa ou grave $(\mathrm{QI}<50)$ e DI leve $(\mathrm{QI}=50-70)$. Esse é um sistema simples, com base no escore obtido pelo indivíduo em um teste de inteligência confiável, que deve ser realizado em conjunto com um sistema de classificação do comportamento adaptativo.

2) Quanto à etiologia, a DI é o resultado comum de um grande número de patologias. Essas patologias têm componentes biológicos, psicológicos e sociais, e sua abordagem deve ser multidisciplinar. Embora em todos os casos esses três componentes estejam presentes, em cada um deles existe um predominante cuja determinação é importante para a conduta terapêutica.

\section{Fatores de risco/Defeitos associados}

Enquanto a DI leve costuma ser um deficit isolado, a DI grave, em geral, é acompanhada por outros deficit que limitam a adaptação dos afetados e o seu prognós- 
tico. Entre esses deficit estão: paralisias cerebrais mais graves, problemas visuais, como estrabismo e defeitos de refração, crises convulsivas, deficit de comunicação, problemas alimentares, deficit de atenção e hiperatividade, distúrbios psiquiátricos e pervasivos, como transtornos do espectro autista (TEA). Estudos epidemiológicos têm mostrado risco maior para a ocorrência de DI em crianças do sexo masculino, com malformações congênitas, especialmente as que envolvem o sistema nervoso central, associadas ou não a anomalias cromossômicas. Outros fatores predisponentes são: baixo peso ao nascer, prematuridade, nascidos de mães com baixa escolaridade e com idade avançada e afrodescendentes. ${ }^{7}$

\section{Etiologia da DI}

Em termos didáticos, as causas de DI podem ser agrupadas, de acordo com o tempo de ocorrência em pré-natais, perinatais e pós-natais. Esta classificação facilita o seu entendimento e tem repercussões na avaliação dos pacientes, orientando os exames a serem solicitados.

Abordaremos a seguir algumas das causas mais prevalentes de DI.

\section{Causas pré-natais}

Neste grupo de causas pré-natais, incluem-se as doenças de origem ambiental, atuando como teratógenos, como as infecções congênitas (TORCH), a exposição intraútero a medicamentos como os anticonvulsivantes e a hiperfenilalaninemia materna, entre outros. Dentre estes teratógenos salientamos o uso do álcool e a ocorrência da síndrome do álcool fetal (SAF).

A SAF se caracteriza por um grupo de anormalidades físicas, comportamentais e cognitivas em indivíduos que sofreram exposição pré-natal ao álcool, sendo considerada uma das causas mais comumente identificáveis de DI. As estimativas são de que a síndrome acomete 5,2 por 10.000 nascidos vivos nos EUA. ${ }^{8}$ Além das alterações dismórficas faciais específicas com fendas palpebrais curtas, sobrancelhas hirsutas, filtrum liso, o quadro clínico pode incluir grandes malformações, como defeitos cardíacos, fenda labial ou palatina, deformidades com redução dos membros e anormalidades do desenvolvimento neurológico, como microcefalia, agenesia/disgenesia do corpo caloso, tremores, hiperatividade, deficiências do aprendizado, retraimento social e distúrbio de conduta em graus variáveis. ${ }^{9}$ Posteriormente, este fenótipo foi ampliado para o que se denomina desordem do espectro do álcool fetal, para os casos nos quais não se enquadram nos critérios diagnósticos clássicos, mas mostram deficiência intelectual limítrofe ou borderline (QI na faixa de 70-79) e escores menores em testes de aritmética, processamento de números, memoria visual, linguagem, função motora, entre outros. A necessidade de um diagnóstico e intervenção precoces é enfatizada pela possibilidade de melhora na produtividade escolar e adaptação social, e pelas evidências de que a ocorrência de problemas secundários, como transtornos psiquiátricos e abuso de substâncias, pode ser prevenida. ${ }^{10}$ Daí a importância do reconhecimento precoce pelo pediatra deste grupo de condições. Tendo em vista que desordens neurocomportamentais têm sido documentadas com exposições intraútero ao álcool em qualquer período da gestação e devido ao fato que as doses consideradas "seguras" para a gestação não são conhecidas, orienta-se como importante medida de prevenção que a gestante abstenha-se do uso do álcool.

Chamamos a atenção para a recente associação da ocorrência de microcefalia em recém-nascidos de mães expostas durante a gravidez ao vírus zika no Brasil, que, num cenário de epidemia no Brasil, aumentou a preocupação quanto a vigilância do desenvolvimento destas crianças frente ao alto risco de evoluírem com grave AGD. ${ }^{11,12}$

\section{Doenças genéticas}

No momento, cerca e 25 a 50\% das causas identificadas de DI são de origem genética. ${ }^{2}$ Entre as etiologias de origem genética, que são múltiplas, as mesmas podem ser oriundas de anomalias cromossômicas (aneuploidias), de deleções, duplicações e rearranjos submicroscópicos (como variações no número de cópias), ou desordens monogênicas decorrentes de variações patogênicas em genes autossômicos, genes ligados ao cromossomo X ou menos comumente, em genes mitocondriais ou decorrentes de mecanismos genéticos não tradicionais como dissomia uniparental, (UDP - a exemplo das síndromes de Angelman, Prader Willi, Russel-Silver etc.). Ao pesquisar o termo "mental retardation" no banco de dados da internet On-line Mendelian Inheritance in Man (http://www.ncbi.nih. nlm.gov/OMIM), ${ }^{13}$ foram geradas, em abril de 2016, 1.128 entradas de síndromes genéticas com retardo mental (deficiência intelectual) associado.

Dentre as síndromes que cursam com deficiência intelectual em graus variáveis mais facilmente suspeitáveis pelo pediatra, citamos as síndromes do $\mathrm{X}$ Frágil, a síndrome de Rett, síndrome de Sotos e algumas síndromes de microdeleções cromossômicas como as síndromes de Williams, Prader Willi e Rubinstein 


\section{Artigo de revisão}

Taiby por suas manifestações clássicas na infância.

O progresso na identificação de genes responsáveis pelo AGD e DI tem permitido compreensão adicional da base molecular do aprendizado e da memória, fundamental para a compreensão da cognição e do intelecto, visando o desenvolvimento de abordagens farmacológicas e possíveis terapias gênicas. ${ }^{4}$

\section{Erros inatos do metabolismo}

No contexto das doenças genéticas, os erros inatos do metabolismo (EIM) representam 10\% das doenças genéticas. Apresentam impacto no sistema de saúde, pois respondem por cerca de $6-8 \%$ das admissões hospitalares pediátricas e por até $25 \%$ dos casos de morte súbita. Por esta razão, deveriam constituir como primeira suspeição diagnóstica diante da criança gravemente enferma ou que evolui com deformidades ou perda das suas funções neurocognitivas. ${ }^{14}$ Diante da grande multiplicidade de sinais e sintomas de grupos etiológicos, e também pelo fato de o acesso diagnóstico ser restrito a poucos laboratórios especializados, os EIM representam ainda uma dificuldade diagnóstica. Entretanto, a realização do diagnóstico é compensada pelas possibilidades terapêuticas específicas e pela oferta de aconselhamento genético, considerando que a maioria dos EIM apresentam herança autossômica recessiva e, portanto, com alto risco de recorrência na prole do casal.

Digno de nota é o grupo dos defeitos congênitos da glicosilação (congenital disorders of glycosylation - CDG's), já com 70 formas descritas ${ }^{15}$ que apresenta elevada frequência e grande variabilidade clínica, tendo como elemento de ligação somente a sua fisiopatogenia.

São defeitos na produção ou edição nas organelas, dos glicoconjugados, essenciais no metabolismo celular, muito preservados evolutivamente. Sua deficiência manifesta-se de maneira multissistêmica, podendo apresentar-se como encefalopatia, cardiomiopatia, atrasos do desenvolvimento, distribuição anômala de gordura em tecidos supraglúteos, perda visual, hepatopatia progressiva, entre outros. ${ }^{16}$ Uma dificuldade para seu diagnóstico é a necessidade de testes específicos - a focalização isoelétrica da transferrina é o mais utilizado, porém nem todas as formas são detectáveis com essa abordagem. Esta dificuldade está sendo contornada com a aplicação da espectrometria de massas in tandem que vem se estabelecendo como método diagnóstico para estas desordens. ${ }^{17}$ Os testes genéticos mutacionais poderão ser utilizados nos casos em que o diagnóstico bioquímico for confirmado. A identificação da mutação responsável por um EIM num paciente pode acelerar o diagnóstico e torna-se útil para rastreamen- to pré-concepcional ou pré-natal em casais de risco, como aqueles que já tiveram uma criança afetada pela condição. ${ }^{16}$

\section{Causas perinatais e pós-natais}

Estas condições contribuem para uma proporção menor dos casos de DI e a história clínica auxilia na suspeição diagnóstica. Dentre as perinatais, incluímos o kernicterus, meningite, sépsis, hipóxia, hipoglicemia grave, baixo peso associado à prematuridade ou ao retardo no crescimento intrauterino. A mortalidade dos recém-nascidos de muito baixo peso (peso $<=1500$ g) vem, com o progresso da terapia intensiva neonatal, diminuindo. No entanto, a morbidade ainda é significante quanto à ocorrência de DI, paralisia cerebral e convulsões. Causas pré-natais podem se sobrepor às causas perinatais, determinando que o bebê nasça em más condições. ${ }^{3}$

As causas pós-natais contribuem para uma proporção menor dos casos de DI e a história clínica auxilia na suspeição diagnóstica. Situam-se neste grupo traumatismos do sistema nervoso central, meningite, encefalite, hipoxemia grave, hipernatremia grave, hipoglicemia grave, intoxicação por chumbo. A desnutrição proteico calórica na infância, especialmente nos primeiros 24 meses de vida extrauterina, período crucial para o desenvolvimento e crescimento cerebral, tem sido associada à ocorrência de disfunções sinápticas e à consequente DI, além da observação de distúrbios de neurointegração.

\section{Avaliação da criança com DI}

A avaliação etiológica da criança com DI é um processo que necessita de especial atenção, exigindo, em muitos casos, avaliações subsequentes, todas de forma criteriosa, visando à obtenção do diagnóstico correto. Este, muitas vezes obtido com o auxílio do geneticista clínico, tornará viável o aconselhamento genético dos pais do paciente, com implicações em sua vida reprodutiva. Avaliações clínicas interdisciplinares poderão ser muito úteis e se compõem, em geral, de neurologista, endocrinologista e geneticista clínico. Avaliações com oftalmologista, otorrinolaringologista, psiquiatra, cardiologista, poderão ser necessárias, visto que, em muitos casos, a DI não se manifesta de forma isolada.

\section{Anamnese e o exame físico}

A anamnese e o exame físico com ênfase em características morfológicas constituem a base fundamental para os estudos da etiologia da DI, uma vez 
que, acoplados ao exame neurológico podem alcançar chance de detecção diagnóstica de até $80 \%$ dos casos. ${ }^{18}$ A anamnese deve ser obtida da forma mais completa possível, de preferência com os pais ou cuidadores mais próximos da criança, atentando-se para dados específicos descritos a seguir. ${ }^{3}$

$\mathrm{Na}$ história familiar, deve-se averiguar a idade dos pais, nível de escolaridade dos mesmos, consanguinidade, a ocorrência de casos semelhantes, perdas gestacionais, neomortalidade, natimortalidade, malformações congênitas, distúrbios psiquiátricos, autismo, dificuldades escolares, com confecção de heredograma abrangendo três gerações.

Na história gestacional, o pediatra deverá interrogar sobre doenças maternas (epilepsia, hipertermia, fenilcetonúria), uso de medicamentos, exposição ao álcool, a outras drogas e a infecções do grupo TORCH, medidas abortivas, movimentação fetal e crescimento fetais e, sempre que possível, checar os exames realizados durante o pré-natal. Deve-se atentar para o peso, idade gestacional, tipo de parto e motivo em caso de cesárea, índice de Apgar, ocorrência de eventos imprevistos e tratamentos realizados, checando relatórios de alta, além da verificação do teste do pezinho.

$\mathrm{Na}$ história da doença atual procurar identificar época do início dos sinais, caso haja, por exemplo, regressão neurológica com perda das habilidades já adquiridas, mudança nas feições da criança e sintomas que se somem ao atraso de desenvolvimento.

$\mathrm{Na}$ história patológica pregressa, é importante avaliar a ocorrência de internações, convulsões, cirurgias, medicamentos em uso. Ao se obter dados do crescimento e desenvolvimento, atentar para as épocas de aquisição dos marcos do desenvolvimento, terapias instituídas. Também merece ser lembrada a ocorrência de acidentes vasculares cerebrais, além de cardiomiopatia hipertrófica com possíveis manifestações de miopatias mitocondriais.

No transcorrer da anamnese, o pediatra já deverá observar a ocorrência de dismorfias e a existência de um fenótipo clinico característico ou não, bem como o comportamento da criança.

O exame físico deverá ser o mais completo possível, mesmo quando a cooperação e a compreensão do paciente não o permitam. Dados antropométricos (peso, estatura, perímetro cefálico) devem ser sempre aferidos e plotados nos respectivos gráficos de acordo com sexo e idade. Tais achados poderão estar associados a um quadro sindrômico ou não sindrômico. Mais comumente, quando a etiologia da DI é genética, o fenótipo torna-se mais evidente com dismorfias mais grosseiras e mais facilmente perceptíveis ao exame morfológico, caracterizando um quadro sindrômico.

Assim, deve-se ter atenção especial quanto à presença de dismorfias, micro ou macrocefalia, alterações na pigmentação da pele (eventualmente observadas com lâmpada de Wood), alterações em extremidades, baixa estatura e desproporcionalidade do segmento superior em relação ao inferior poderão ser cruciais para o diagnóstico de uma série de síndromes dismórficas, facomatoses e displasias esqueléticas, respectivamente. Malformações menores, que não comprometem a funcionalidade, devem ser procuradas à ectoscopia, lembrando que quanto maior o número de malformações menores encontradas, maior a possibilidade de estar diante de uma criança com malformações maiores internas que põem em risco a vida ou comprometem a funcionalidade do indivíduo.

O fato de estar diante de uma criança dismórfica, não exclui a possibilidade de um erro inato do metabolismo, uma vez que, algumas destas condições, como, por exemplo, as síndromes de Zellweger e de Smith-Lemli-Opitz e as mucopolissacaridoses assim se apresentam. A observação de face grosseira ("infiltrada") ou outras dismorfias faciais, baixa estatura desproporcional, hepatoesplenomegalia, anomalias de pigmentação e textura de cabelo, indicam a necessidade do rastreamento metabólico. Hepatoesplenomegalia pode levantar a suspeita de infecções congênitas ou doenças lisossomais. Hábito marfanoide com DI associada sugere homocistinúria. $^{3}$

O exame neurológico, como já citado, é indispensável, devendo-se observar o comportamento e a comunicação, além da ocorrência de autoagressão, risos involuntários, resposta ao olhar, ao contato tátil e movimentos repetitivos. O exame de fundo de olho poderá contribuir para hipóteses diagnósticas e está indicado especialmente nos casos que apresentam encefalopatias progressivas. Todos os achados devem ser descritos detalhadamente na ficha médica da criança. Documentação com fotografias e filmes dos pacientes, mediante consentimento informado dos responsáveis, poderão ser úteis para o estudo dos casos, em especial daqueles com dismorfias e dos que apresentem distúrbios do movimento e comportamentos anormais. ${ }^{3}$

\section{Exames complementares}

A etapa subsequente à anamnese e ao exame físico é constituída pela solicitação dos exames complementares e deve ser criteriosa, baseando-se nas hipóteses 


\section{Artigo de revisão}

diagnósticas aventadas, na idade do paciente, gravidade e complexidade da patologia e urgência dos pais em relação ao planejamento reprodutivo. Atualmente, um arsenal de exames diagnósticos se encontra disponível, cabendo ao pediatra e a outros profissionais médicos, em especial ao neurologista e ao geneticista clínico avaliar os que de fato são indispensáveis e em que momento solicitá-los, ponderando além dos benefícios citados, as desvantagens, tais como o desconforto para o paciente, a ansiedade dos pais pela espera dos resultados dos exames, além dos custos.

Reavaliações seriadas da criança ao longo do tempo, às vezes durante anos, poderão ser úteis para o diagnóstico, considerando que os fenótipos clínicos e comportamentais tendem a se modificar à medida que o paciente cresce, permitindo a definição de determinadas condições.

Serão discutidos, de maneira breve, os exames mais utilizados na investigação diagnóstica da criança com AGD/DI, constituídos de cinco principais grupos: estudos citogenéticos e citogenéticos moleculares (FISH, MLPA), ensaio genômico comparativo, análises mutacionais para a síndrome do X Frágil e síndrome de Rett, testes para pesquisa de erros inatos do metabolismo, exoma e sequenciamento do genoma; e estudos de neuroimagem.

\section{Cariótipo banda G}

As anomalias cromossômicas são responsáveis por um número significativo de pacientes com DI. O estudo citogenético com bandeamento GTG e utilizando-se técnicas de alta resolução (500 a 800 bandas) permite a detecção de perdas ou duplicações de segmentos cromossômicos até $5 \mathrm{Mb}$. E se mantém, em nosso meio, como o primeiro exame genético para a investigação de pacientes com SGD e DI. ${ }^{3}$ Também indicado para as síndromes cromossômicas clássicas, decorrentes de não disjunção cromossômicas (aneuploidias), a exemplo da síndrome de Down (trissomia do cromossomo 21), síndrome de Edwards (trissomia do cromossomo 18), síndrome de Patau (trissomia do cromossomo 13), síndrome de Turner (monossomia do cromossomo X) e para as grandes deleções como a síndrome do miado do gato (deleção 5p), facilmente suspeitadas pelo pediatra a partir do exame clínico-morfológico.

\section{FISH e MLPA}

O método do FISH, do inglês flourescent in situ hybridization, é utilizado para a detecção de deleções ou duplicações entre 1 a 5 Mb de DNA, utilizando-se de sondas locus específicas e, portanto, não é indicado para buscas genômicas de variantes no número de cópias (CNV, do inglês copy number variants) do genoma. Está indicado diante de suspeitas de síndromes específicas de microdeleções como, por exemplo, as síndromes de Williams, Di George, Smith-Magenis, Rubistein-Taybi, associação WAGR, dentre muitas outras síndromes de microdelação emergentes descritas. ${ }^{19}$ Outra técnica de citogenética molecular, como a multiple ligant probe amplification (MLPA), por exemplo, disponível em laboratórios especializados, também poderá ser empregada para o diagnóstico de diversas síndromes de microdeleção ou microdeleção cromossômica, permitindo a detecção de variação no número de cópias de até 50 sequências genômicas ao mesmo tempo. ${ }^{19}$

\section{Ensaio genômico comparativo(arraycgh)}

O emprego do ensaio genômico comparativo (array-comparative genomic hybridization - array cgh) tem permitido a detecção de variações no número de cópias (CNV) no genoma humano, em ao menos 20\% dos casos nos indivíduos com DI ou AGD em que o cariótipo foi normal, a partir da análise de microarranjos do DNA. ${ }^{20}$ Tais variações são de caráter submicroscópico não detectáveis pelos métodos da citogenética clássica.

Chamamos assim, a atenção para as alterações cromossômicas submicroscópicas em uma resolução de até $100 \mathrm{~kb}$, passíveis de detecção em frequências que variam de 4 a $34 \%$ dos pacientes com AGD/DI, incluindo pacientes com autismo associado. ${ }^{20-22}$ Estas diferentes taxas de detecção na variação no número de cópias no genoma humano se justificam pela utilização de arrays com quantidades diferentes de sondas moleculares, com aumento considerável da capacidade diagnóstica a partir da utilização de um número maior de sondas entre os diversos grupos e também a partir dos critérios clínicos de seleção. ${ }^{19-21}$ Observa-se uma chance maior de positividade nos casos de crianças com malformações congênitas associadas, como microcefalia, cardiopatia congênita, dentre outras. ${ }^{20,22}$ Recentemente, a história familiar positiva para DI, AGD e malformações congênitas também foram considerados bons indicadores para a detecção de rearranjos cromossômicos patogênicos, nos quais achados como anomalias oculares, perda auditiva, sinais neurológicos, discromia cutânea e problemas endocrinológicos podem ser bons preditores de CNVs patológicas, em especial na investigação de pacientes com autismo (TEA) associado. ${ }^{23}$

O array CGH tem sido considerado o exame de primeira linha para a investigação dos atrasos de de- 
senvolvimento e DI sem causa definida, assim como para os casos de autismo. ${ }^{4,24}$ Tal como observado com cariótipo, alguns resultados do array cgh, entretanto, podem ter significado incerto, uma vez que algumas deleções ou duplicações ainda não estejam claramente definidas como patogênicas ou benignas. De um modo geral, as CNVs assumem as seguintes interpretações emitidas pelos especialistas em bioinformática e biologia molecular: (1) patogênicas (anormais, observadas em síndromes bem reconhecidas, variantes de novo e grandes alterações); (2) variantes de significado desconhecido e (3) provavelmente benignas. Colaborações internacionais têm se alinhado na tentativa continua de reavaliar, periodicamente, o significado da variabilidade dos resultados em bancos de dados genômicos, em especial, o das variantes incertas para as quais as interpretações permanecem ambíguas. ${ }^{4}$

Orientamos, assim, que a interpretação e aconselhamento acerca dos resultados anormais de array cgh e de significado desconhecido ou incerto devam ser realizados sempre por médico geneticista em colaboração com laboratórios e plataformas de referência. A figura 1 mostra o gráfico (anormal) de um array cgh de uma criança avaliada por AGD, deficit no crescimento e dismorfias crâniofaciais; evidenciando-se uma perda no número de cópias da região cromossômica 5p15.33p15.31, abrangendo aproximadamente 8,245 Mb, e um ganho na região cromossômica 14q31.1q32.33, de cerca de $24,958 \mathrm{Mb}$, sugerindo uma aparente translocação não balanceada, entre os cromossomos 5 e 14.

\section{Análise molecular para a síndrome do $\mathrm{X}$ frágil e para síndrome de Rett}

Até o momento, poucas condições monogênicas bem caracterizadas do ponto de vista molecular e clínico (fenótipos mais facilmente reconhecíveis) são testadas em laboratório de forma rotineira durante uma avaliação diagnóstica. Dentre estas, citamos a síndrome do X frágil e a síndrome de Rett.

Recomenda-se a pesquisa molecular para a mutação do X frágil a todos os pacientes com DI sem etiologia estabelecida, meninos e meninas, o que se justifica pela sua alta prevalência, certa dificuldade diagnóstica na faixa etária pediátrica e pela preciosa provisão do aconselhamento genético familiar de membros sob o risco de serem portadores da pré-mutação, considerando medidas de prevenção secundária. Em termos de testes diagnósticos, preconiza-se a utilização da técnica do PCR e ulterior análise por sequenciamento automático, obtendo-se o número de repetições CGG.

A pesquisa molecular para a síndrome de Rett a partir do sequenciamento do gene MECP2 está indicada em todas as meninas com quadro de regressão neurológica, perda da fala, movimentos estereotipados, classicamente das mãos, microcefalia, convulsões e DI. A análise molecular tem ampliado o espectro fenotípico da síndrome de Rett para as meninas com DI leve, TEA e para meninos com encefalopatia grave. ${ }^{4,25}$

\section{Triagem para EIM}

Por responderem por até $5 \%$ dos casos de AGD/DI, recentemente, o uso de testes específicos foi incluído de maneira formal na rotina de investigação da criança com AGD ou DI pelo seu potencial de tratamento e consequente impacto no desfecho clínico, com diminuição da morbidade e melhora na qualidade de vida. Tais testes incluem a pesquisa no sangue de homocisteína, aminoácidos (por cromatografia e acilcartininas,

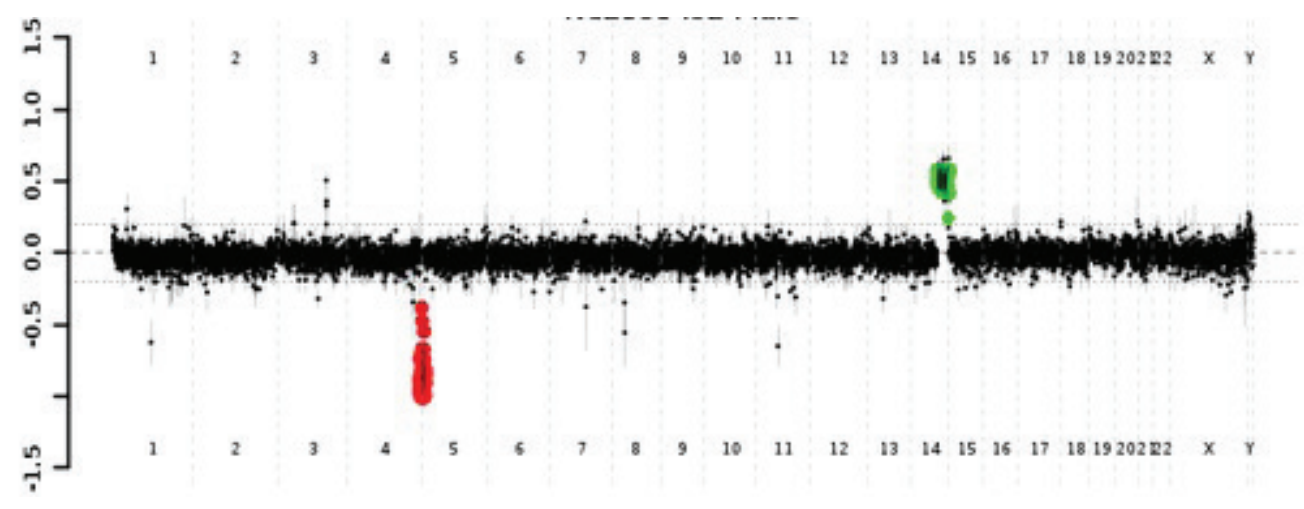

Figura 1. gráfico de uma análise cromossômica por microarray (CMA). Revela uma perda no número de cópias da região cromossômica 5p15.33p15.31, abrangendo aproximadamente 8,245 Mb, e um ganho na região cromossômica 14q31.1q32.33, de aproximadamente $24,958 \mathrm{Mb}$, sugerindo uma aparente translocação não balanceada, entre os cromossomos 5 e 14 . 


\section{Artigo de revisão}

por espectrometria de massas in tandem) e na urina, a dosagem de ácidos orgânicos (por cromatografia/ espectrometria de massas in tandem), rastreamento para mucopolissacarídeos (glicosaminoglicanos) e oligossacarídeos (por cromatografia) e focalização isoelétrica da transferrina e a espectrometria de massas para a transferrina, teste este recém-incorporado na rotina de investigação dos distúrbios ou desordens congênitas da glicosilação, dentre os principais. ${ }^{4,16}$ As testagens ampliadas e investigações mais aprofundadas devem respeitar um raciocínio clínico, seguindo-se um algoritmo, direcionando-se as pesquisas de acordo com os resultados obtidos nos testes de triagem urinária e/ ou plasmática, e eventualmente aplicando-se sequenciamento de nova geração para detecção de mutações associadas a determinadas condições, sob orientação de especialistas.

\section{Exoma/sequenciamento do genoma}

Dentre as tecnologias emergentes estão disponibilizadas aquelas que se destinam ao sequenciamento do exoma (WES - whole exome seguencing) e ao sequenciamento do genoma (WGS - whole genome sequencing). O exoma tem se tornado uma ferramenta popular na investigação de pacientes com condições genéticas heterogêneas, sobretudo aquelas com fenótipos neurocognitivos (AGD/DI, convulsões, TEA) e malformações congênitas. Sua utilidade clinica reside no fato de haver um aumento de taxas diagnósticas, em especial nas populações consanguíneas, permitindo intervenções médicas mais apropriadas, escolhas reprodutivas mais conscientes, além de evitar exames diagnósticos adicionais. ${ }^{25}$ Estudos também sugerem a possibilidade de expansão de fenótipos de diversas condições monogênicas e identificação de novos genes candidatos a doenças cuja identificação seria impossível a partir do emprego de outras técnicas. ${ }^{26}$ Tanto o sequenciamento do exoma (WES), quanto o sequenciamento de todas as regiões do genoma (WGS) são ferramentas poderosas para a descoberta de genes de diversas condições geneticamente determinadas independentes de ser o alvo do que está se procurando responder e pode, assim, auxiliar discussões éticas importantes, principalmente ao serem identificadas doenças incuráveis e/ou de aparecimento na idade adulta. Sugerimos que solicitações mais específicas e/ou que se utilizem destas tecnologias sejam efetuadas mediante parecer de um geneticista clínico.

Por fim, sinalizamos que, mesmo com o auxílio dessas novas abordagens laboratoriais, muitos pacientes com AGD ainda permanecerão sem diagnóstico etioló- gico. Essa limitação demonstra que ainda há espaço para a aplicação de metodologias inovadoras na investigação de novos mecanismos que possam estar na origem dos AGD, da DI e transtornos do desenvolvimento. Mas, a parcela de pacientes que alcançar um diagnóstico por meio dessa nova abordagem, será contemplada pelos diversos benefícios já elencados.

A tabela 2 mostra, de forma resumida, exemplos clássicos de síndromes que cursam com deficiência intelectual, utilizando-se uma classificação etiológica, descrição clínica e exames diagnósticos indicados, que serão pormenorizados a seguir.

\section{Neuroimagem}

O pediatra em geral deseja saber se toda criança ou adolescente com DI precisa de avaliação neurorradiológica. É provável que a maioria dos pacientes acabe sendo submetida a uma tomografia computadorizada (TC) ou ressonância magnética (RNM). Tais exames têm uma taxa de resultados positivos mais altos quando a anamnese detecta crises convulsivas ou história de perda de marcos do desenvolvimento ou quando o exame físico revela microcefalia ou macrocefalia e espasticidade. ${ }^{4}$

A TC de crânio é o exame de escolha quando o objetivo é pesquisar calcificações intracranianas, como na suspeita de uma infecção congênita do grupo TOR$\mathrm{CH}$. A ressonância magnética do encéfalo é oportuna na investigação de malformações cerebrais como a holoprosencefalia, heterotopia cortical, lissencefalia, agenesia do corpo caloso e displasia septo-óptica, todas as quais estão fortemente associadas a DI. A ressonância magnética também fornece informações valiosas sobre a mielinização da substância branca, etapa crucial do neurodesenvolvimento nos primeiros anos de vida que muitas vezes é comprometida nas síndromes relacionadas com AGD/DI (p. ex., síndrome de Smith-Lemli-Optiz, distrofias musculares congênitas). Uma técnica de neuroimagem funcional bastante utilizada é a espectroscopia de prótons por ressonância magnética, que permite investigar os erros inatos do metabolismo através da detecção de anormalidades bioquímicas no tecido cerebral. ${ }^{3}$

\section{Transmissão do diagnóstico, medidas de intervenção/suporte e tratamento}

Após a transmissão do diagnóstico de forma cuidadosa e de previsões prognósticas bastante prudentes quando solicitadas, o pediatra deve oferecer com postura assertiva, as estratégias de intervenção, suporte e 
Tabela 2. Manifestações clínicas e testes diagnósticos de condições genéticas que cursam com deficiência intelectual.

\begin{tabular}{lllll}
\hline Síndrome genética & \multicolumn{1}{c}{ Causa } & \multicolumn{1}{c}{ Manifestações clínicas } & \multicolumn{1}{c}{ Teste diagnóstico } \\
\hline Síndrome do miado do gato & $\begin{array}{l}\text { Deleção do cromosso- } \\
\text { mo } p\end{array}$ & $\begin{array}{l}\text { Microcefalia, pregas epicânticas, choro } \\
\text { fraco, deficit de crescimento }\end{array}$ & $\begin{array}{l}\text { Cariótipo banda } \mathrm{G} \text { em sangue } \\
\text { periférico }\end{array}$ \\
\hline Síndrome de Wolf-Hirschorn & $\begin{array}{l}\text { Deleção do cromosso- } \\
\text { mo 4p16.3 }\end{array}$ & $\begin{array}{l}\text { Fronte do capacete grego, fenda } \\
\text { lábio-palatal, cardiopatia congênita }\end{array}$ & $\begin{array}{l}\text { Cariótipo banda G em sangue } \\
\text { periférico }\end{array}$ \\
\hline Associação CHARGE & Microduplicação 8q12 & $\begin{array}{l}\text { Atresia de coanas, cardiopatia congêni- } \\
\text { ta, deficit de crescimento, hipoplasia } \\
\text { genital }\end{array}$ & $\begin{array}{l}\text { FISH* para microdeleção 8q12; } \\
\text { MLPA ou array CGH }\end{array}$ \\
\hline
\end{tabular}

\begin{tabular}{|l|l|}
$\begin{array}{l}\text { Síndrome de Phelan-Mcder- } \\
\text { mid }\end{array}$ & $\begin{array}{l}\text { Microdeleção do cro- } \\
\text { mossomo 22q13; mu- } \\
\text { tação gene SHANK3 }\end{array}$ \\
\hline $\begin{array}{l}\text { Síndrome de Prader-Willi } \\
\text { Microdeleção do cro- } \\
\text { mossomo 15q11 }\end{array}$ \\
\hline Síndrome de Williams & $\begin{array}{l}\text { Microdeleção do cro- } \\
\text { mossomo 7q11.23 }\end{array}$ \\
\hline Síndrome de Smith Magenis & $\begin{array}{l}\text { Deleção do cromosso- } \\
\text { mo 17p11.2 }\end{array}$
\end{tabular}

\begin{tabular}{|l|l|}
$\begin{array}{l}\text { Síndrome velocardiofacial (Sd. } \\
\text { Shprintzen) }\end{array}$ & $\begin{array}{l}\text { Deleção do cromosso- } \\
\text { mo 22q11.2 }\end{array}$ \\
\hline Síndrome de Sotos & $\begin{array}{l}\text { Mutações de ponto no } \\
\text { gene NSD1 }\end{array}$ \\
\hline Síndrome do X Frágil & $\begin{array}{l}\text { Repetição do triplete } \\
\text { CGG no gene FMR-1 } \\
\text { em Xq27 }\end{array}$ \\
\hline Síndrome de Rett & $\begin{array}{l}\text { Mutações no gene } \\
\text { MECP2 em Xq28 }\end{array}$ \\
\hline
\end{tabular}

\begin{tabular}{l|l}
$\begin{array}{l}\text { Defeitos congênitos da gli- } \\
\text { cosilação }\end{array}$ & $\begin{array}{l}\text { Heterogeneidade aléli- } \\
\text { ca }\end{array}$ \\
\end{tabular}

Mucopolissacaridose I

Mutações no gene IDUA
Hipotonia acentuada, dismorfias menores, epilepsia, transtornos do espectro autista

Hipotonia, olhos amendoados, pinçamentobitemporal, acromicria, deficiência de GH

Baixa estatura, face de "fadinha", voz rouca, estenose aórtica supravalvar, hipercalcemia, hipercalciúria

Fronte ampla,fendas oculares obliquas, miopia, distúrbios de comportamento (automutilação) e alterações do ciclo circadiano (sono-vigília)

Fenda labiopalatal, cardiopatia conotruncal, plaquetopenia, dedos afilados, malformações do sistema nervoso central

Macrossomia, macrocefalia, leve ptose palbepral, avanço na idade óssea

Atraso na linguagem, macrocrania, fronte ampla, flacidez ligamentar, macro-orquidismo, transtorno do espectro autista

Regressão neurológica, estabilização do perímetro cefálico, estereotipias de mãos

Mamilos invertidos, depósitos de gordura em região supraglútea, hipoplasia cerebelar, perda visual, convulsões,

Face infiltrada, baixa estatura, rigidez articular, deformidades esqueléticas, hepatoesplenomegalia, opacificação de córnea

Mucopolissacaridose II Mutações no gene IDS Face infiltrada, baixa estatura, rigidez articular, deformidades esqueléticas, hepatoesplenomegalia

Array cght sequenciamento do gene SHANK3

FISH ou MLPA§ para microdeleção $15 q 11$

FISH ou MLPA para microdeleção

FISH ou MLPA para microdeleção 17p11.2

FISH paramicrodeleção 22q11.2, array cgh

Sequenciamento do gene NSD1

Pesquisa do número de repetições CGG por PCR seguido sequenciamento automático

Sequenciamento do gene MECP2

Teste da focalização isoelétrica da transferrina (triagem)

Dosagem da atividade enzimática da alfaiduronidase

Dosagem da atividade enzimática da iduronatosulfatase

*FISH: fluorescent in situ hybridization; †Array cgh: comparative genomic hybridization; §MLPA: multiple ligant probe amplification. 
tratamentos específicos quando disponíveis. Não se esquecendo dos aspectos de atenção primária, que devem ser os mesmos dispensados às crianças da mesma idade cronológica, além das necessidades especiais. A Academia Americana de Pediatria (APA) tem dedicado diversos tópicos em seu site enfatizando a importância do pediatra no atendimento adequado dos pacientes com síndromes genéticas e, de forma didática, disponibiliza orientações diversas desde a abordagem familiar à supervisão antecipatória da saúde destes pacientes. Convidamos o leitor a consultá-lo para enriquecimento de sua prática. ${ }^{28}$

Caberá muitas vezes ao pediatra a emissão de laudos diagnósticos tendo em vista a inserção em programas de reabilitação e para obtenção de benefícios sociais. A interdisciplinaridade na assistência a estes pacientes é também recomendada, visando à otimização dos cuidados. Sinalizamos, por fim, que o pediatra deverá ficar atento quanto ao maior risco de abandono e maus tratos que ocorre entre crianças e adolescentes com DI, atuando como um defensor de seus direitos juntos às diversas representações da sociedade

\section{Referências}

1. Victora CG, Aquino EML, Maternal and child health in Brazil: progress and challenges; Lancet 2011; 377:1863-76

2. Srour M, Shevell M . Genetics and the investigation of developmental delay/intellectual disability. Arch Dis Child 2014: 99-386-389). Arch Dis Child. 2014 Apr;99(4):386-9.

3. Boy Silva RT, Vasconcelos MM, Paiva IS. A criança com deficiência intelectual - aspectos genéticos, diagnósticos e terapêuticos. In:Campos Jr D, Burns ARB, Lopes FA, org. Tratado de Pediatria. São Paulo: Ed. Manole, 2014. p.1315-22.

4. Moeschler JB, Shevell M and COMMITTEE ON GENETICS. Comprehensive Evaluation of the Child With Intellectual Disability or Global Developmental Delays. Pediatrics 2014;134;e903. Downloaded from pediatrics.aappublications. org by guest on March 6, 2016.

5. Shevell Ml, Ashwal S, Donley D et al. Practice parameter: evaluation of the child with global developmental delay. Neurology 2003;60(3):367-80.

6. Sherr EH, Shevell MI. Global developmental delay and mental retardation/intellectual disability. In: Swaiman KF, Ashwal S, Ferriero DM, Schor NF.eds Pediatric neurology: principles and practice. 5th edn. Philadelphia: Elsevier Saunders, 2012:554-74

7. Boy Silva RT. Estudo clínico e epidemiológico de indivíduos portadores de retardo mental inseridos no programa de educação especial do Estado do Rio de Janeiro. Rio de Janeiro, Instituto Fernandes Figueira, Fundação Oswaldo Cruz, 1996. Dissertação, $101 p$

8. Jacobs EA, Copperman SM, Joffe A et al. Fetal alcohol syndrome and alcohol-related neurodevelopmental disorders. Pediatrics 2000;106(2):358-361.

9. Jones KL, Smith DW. Recognition of the fetal alcohol syndrome in early infancy. Lancet. 1973;2:999-1001.

10. Momino W, Sanseverino MTV, Schüler-Faccini L. A exposição pré-natal ao álcool como fator de risco para comportamentos disfuncionais: o papel do pediatra. J. Pediatr. (Rio J.) [Internet]. 2008 Aug [cited 2017 Apr 04] ; 84( 4 Suppl): S76-S79. Available from: http://www.scielo.br/scielo.php?script=sci_art-
text\&pid=S0021-75572008000500011\&lng=en. http://dx.doi. org/10.1590/S0021-75572008000500011.

11. WHO. 2016 IHR Procedures concerning public health emergencies of international concern (PHEIC). http://www.who.int/ $\mathrm{ihr} /$ procedures/pheic/en/. Accesso em 3 de fevereiro de 2016.

12. Oliveira WK, Cortez-Escalante J, De Oliveira WTG. 2016. Increase in Reported Prevalence of Microcephaly in Infants Born to Women Living in Areas with Confirmed Zika Virus Transmission During the First Trimester of Pregnancy - Brazil, 2015.

13. OMIM (Online Mendelian Inheritance in Man). Disponível em <http://www.ncbi.nih.nlm.gov/OMIM>. Acesso em 15 de abril de 2016.

14. Wajner M, Wannmacher CMD, Gaidzinski D, et al. Detection of inborn errors of metabolism in patients of pediatric intensive care units of Porto Alegre, Brazil. Comparison between the prevalence of such disturbances in a selected and an unselected sample. Brazilian Journal of Genetics. 1986, IX: 331-340.

15. Scott K, Gadomski T, Kozicz T, et al. Congenital disorders of glycosylation: new defects and still counting. J Inherit Metab Dis. 2014 May 15.

16. Boy RT, Guida G. Aspectos Diagnósticos dos Erros Inatos do Metabolismo na Infância. Revista Inovar Saúde. 2014;8:54-58.

17. Wada Y. Mass spectrometry of transferrin glycoforms to detect congenital disorders of glycosylation: Site-specific profiles and pitfalls. 2016 Apr 20. [Epub ahead of print]. Acesso em 23 de abril de 2016.

18. van Karnebeek CDM, Jansweijer MCE. Diagnostic investigations in individuals with mental retardation: a systematic literature review of their usefulness. European Journal of Human Genetics. 2005;13:6-25.

19. Weise A, Mrasek K, Klein E, et al. Microdeletion and microduplicaton syndromes. J Histochem Cytochem. 2012 May;60(5):346-358.

20. Siggberg L, Ala-Mello S, Jaakkola E, et al. Array CGH in molecular diagnosis of mental retardation - A study of 150 Finnish patients. Am J Med Genet A. 2010 Jun;152A(6):1398-410.

21. Tucker T, Montpetit A, Chai D, et al. Comparison of genome-wide array genomic hybridization platforms for the detection of copy number variants in idiopathic mental retardation. BMC Med Genomics. 2011;4:25.

22. Xiang B, Zhu H, Shen Y, et a. Genome-wide oligonucleotide array comparative genomic hybridization for etiological diagnosis of mental retardation: a multicenter experience of 1499 clinical cases. J Mol Diagn. 2010 Mar;12(2):204-12

23. Cappuccio G, Vitiello F, Casertano A, et al. New insights in the interpretation of array-CGH: autism spectrum disorder and positive family history for intellectual disability predict the detection of pathogenic variants. Ital J Pediatr. $2016 \mathrm{Apr}$ 12;42(1):39.

24. Battaglia A, Carey JC. Diagnostic evaluation of developmental delay-mental retardation: an overview. Am J Méd Genet2003;117C:3-14.

25. Heilstedt HA, Shahbazian MD, Lee B. Infantile hypotonia as a presentation of Rett syndrome. Am J Med Genet. 2002;111:238-242.

26. Iglesias A, Anyane-Yeboa K, Wynn J et al. The usefulness of whole-exome sequencing in routine clinical practice. Genet Med. 2014 Dec;16(12):922-31. Epub 2014 Jun 5. Acesso em 12 de abril de 2016.

27. Yavarna T, Al-Dewik N, Al-Mureikhi M, et al. High diagnostic yield of clinical exome sequencing in Middle Eastern patients with Mendelian disorders. Hum Genet. 2015 Sep;134(9):96780. Epub 2015 Jun 16. Acesso em 10 de abril de 2016.

28. American Academy of Pediatrics. A Toolkit to Improve Care for Pediatric Patients with Genetic Conditions in Primary Care. Disponível em: htps://geneticsinprimarycare.aap.org/Documents/ Think\%20Genetics_FINAL.pdf Acesso em 23 de abril de 2016. 